\title{
DEVELOPMENT OF PLANT MONITORING AND CONTROL MODULE IN AN INDUSTRIAL POWER PLANT
}

\author{
EkpoEmem Patrick ${ }^{1}$, James Eke ${ }^{2}$, EgoigweSochima Vincent ${ }^{3}$, Araoye Timothy \\ Oluwaseun ${ }^{4}$ and JegedeAdegboyega Koleola ${ }^{5}$ \\ ${ }^{1,2}$ Department of Electrical and Electronics Engineering, Enugu StateUniversity of Science \\ and Technology, Enugu Nigeria. \\ ${ }^{3,4}$ Department of Mechatronics Engineering, University of Nigeria, Nsukka, Nigeria. \\ ${ }^{5}$ Department of Electrical and Electronics Engineering, University of Abuja, Nigeria.
}

\section{Abstract}

The industrial power plant comprises at least one generator, which is electronic on the operation of the plant. The output current, output voltage and operating temperature of the generators in the plant analyzed the state of the power plant. This paper develops industrial power plant control to monitor the output current, voltage and operating temperature of a generator.MPLAB IDE software was used to carry out simulations to monitor and control industrial power plant. The ACS 758 hall effect current sensor, LM35 temperature sensor, a special step down transformer and a PIC16F877A microcontroller was put together to develop a module which records very high accuracy in monitoring the industrial power plant.

Keywords: industrialPower Plant, Control, Monitor, module, MPLAB IDE, Microcontroller, Simulation.

\subsection{Introduction}

Power system plant is an industrial device which converts energy into electrical power when one or more generators are applied into the system [2]. The secondary energy of electricity is observed when primary sources of energy are converted, example are natural gas, coal, solar, nuclear or wind energy. To generate electricity the energy sources can be renewable or nonrenewable, but electricity can be neither renewable nor non-renewable[2]. Therefore energy conversion enhanced the productivity of power plant.

Power Industrial generation is the concept where customers required reducing utility expenses when generating the adequate electricity needed and production of heat.[1]; hence ensuring a reliable and flexible power supply for their processes. Electricity and heating are major cost factors for industrial plants. That means there's a long-term cost benefit in the consumer having their own power plant at their factory, mining, or production facility [3]. The trends towards managing increased power generation and usage require constant improvement in the monitoring and control of power system parameters. Industrial power plants which are facilities used to generate electricity has electric current and voltage as its output. This output current and voltage also indicates the states of the power plant.

The Proper power management is critical for efficient power generation and utilization. This requires accurate and real-time measurements which are extremely important when making decisions. The output of industrial power plants (whether its wind, hydro, thermal, solar, gas e.t.c ) is designed to meet up with the ANSI standard. Hence, this research paper analyze the module which will help in monitoring the output of industrial power plant in real time so as to ensure that it meets up with proper standard [4]. 


\subsection{Current Transformer}

The Current transformer is used for long time control, circuit protection and monitoring in equipment. Examples are power switched-mode supplies, and also for performing precision current measurements in instrumentation applications [10].According to [9] CTs reform line current into standard values which is suitable for measuring instruments, meters, protective relays, and other similar apparatus. A current transformer always provide two windings normally they are insulated from each other, which is called primary and secondary[7]. The connection of primary winding is normally in series with the circuit carrying the line current $\mathrm{t}$, and the connection of secondary winding is attached to instruments or protective devices. The secondary winding supplies are direct proportion to the primary current which is almost without any phase angle difference.[11]

\subsection{Microcontroller Packaging and appearance}

The function of microcontroller is to operate intensively as input/output device with standard pins number. The important of standard pins number is to transfer information of a program into the system memory and also provide power programming process [8]. The 68000 can be analyzed on external memory; hence the pins are connected to address bus functions and data which generate large size. The 40 pin PIC 16F877 produced the comprehensibly from the right. This is the same to 68000 but gives different pins. Thus there are no additional external data or address buses for on- chip program and data memory. Therefore the pin produced high number of digital input/output and lines[5][6][12].

\subsection{Materials and Method}

This research paper develops industrial power plant control to monitor the output current, voltage and operating temperature of a generator. The PIC16F877A microcontroller is used to measure and process information from system hardware, LCD to display information to the user, LM35 temperature sensor to monitor temperature, ACS 758 Hall Effect current sensor to monitor the current, a $240 \mathrm{v}$ to $12 \mathrm{v}$ voltage transformer to monitor the output voltage and buttons for human interaction.

A single $9 \mathrm{v}$ battery is connected to a 7805 regulator IC to provide $5 \mathrm{v}$ for the microcontroller and other system components.

The LM35 are precision for determining temperature sensors of circuit when the voltage output is directly proportional to the temperature of Celsius (Centigrade). Therefore the temperature range of $\mathrm{LM} 35$ is $-55^{\circ}$ to $+150^{\circ} \mathrm{C}$ which is used for circuit operation.

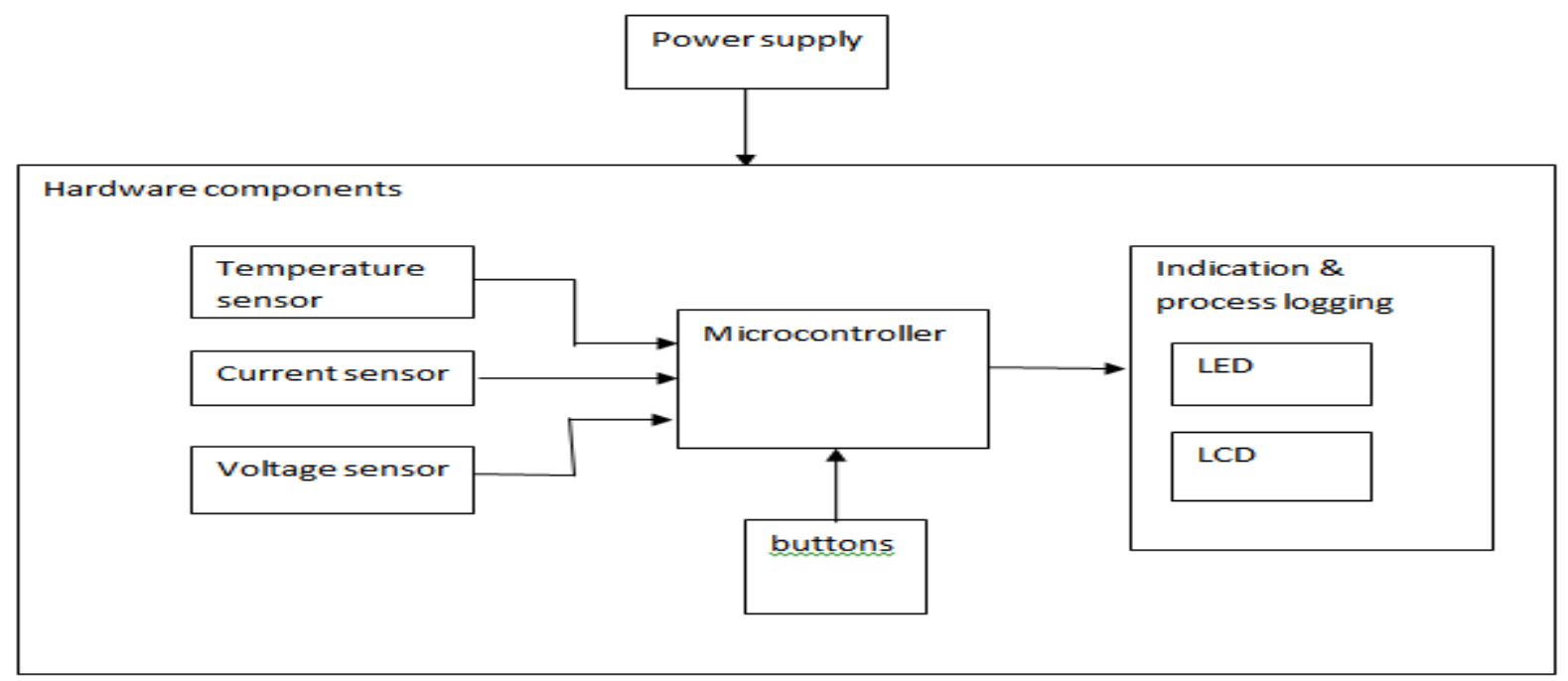

Figure1: system block diagram 


\section{(a) Mathematical modeling}

The current flowing through copper generates a magnetic field that convert hall IC to voltage. The hall transducer is used to optimize the device accuracy and productivity. There is high level intensity of current conductor $\mathrm{dV} / \mathrm{dt}$ and electric fields stray will be discovered, current sensor produces low voltage output ripple, low drift and application of high voltage.

$V_{t}=\frac{k T}{q}$

Where $\mathrm{k}$ is Boltzmann's constant

$\mathrm{T}$ is circuit temperature (Kelvin)

$\mathrm{q}$ is the electronic charge produced in a circuit

$\mathrm{V}_{\mathrm{t}}$ is thermal voltage

The important negative temperature of the emitter base forward biased junction of a transistor is depends on $\mathrm{V}_{\mathrm{BE}}$. The $\mathrm{V}_{\mathrm{BE}}$ equation can be express below:

$V_{B E}=\frac{K T}{q} \ln \frac{I_{C}}{I_{S}}$

Hence

$\mathrm{I}_{\mathrm{C}}=\mathrm{I}_{\mathrm{S}} \mathrm{e}^{\mathrm{VBE} / \mathrm{VT}}$

Where

$\mathrm{I}_{\mathrm{C}}$ is collector current

$\mathrm{I}_{S}$ is saturation current

$\mathrm{V}_{\mathrm{BE}}$ is transistor base emitter voltage

The absolute temperature, $\mathrm{T}$, in the equation above and the quantity $\mathrm{V}_{\mathrm{T}}$, so thermal voltage $(\mathrm{kT} / \mathrm{q})$, gives a positive temperature coefficient. This helps $\mathrm{I}_{\mathrm{C}}$ to gives a positive temperature coefficient.

Hence the device produces low stabilized hall circuit with copper conduction along the path. When load is not connected, the sensor output set at $0.5 \mathrm{Vcc}$.

Assuming that the voltage output from the sensor is $2.7 \mathrm{~V}$, this means that current through the load is $=>$

(Sensor output voltage $-0.5 \mathrm{Vcc}) /$ sensitivity

$\mathrm{Vcc}=5 \mathrm{v}$. Sensitivity $=19.7 \mathrm{mv} / \mathrm{A}($ specified by datasheet $)$

$(2.7-2.5) / 0.0197$

$=10.15 \mathrm{~A}$.

From the transformer equation below:

Turns ratio $=\mathrm{n}=\frac{N P}{N S}=\frac{V P}{V S}$

Primary voltage $=240 \mathrm{v}$

Secondary voltage $=12 \mathrm{v}$

Turns ratio $240 / 12=20$. In other to achieve an output voltage slightly less than $0.5 \mathrm{Vcc}$ at the output of the voltage sensor arrangement; this is necessary to guide against Vcc going slightly below $5 \mathrm{v} .2 .4 \mathrm{v}$ (which is slightly less than $2.5 \mathrm{v}$ ) is chosen to be used.

A $100 \mathrm{k} \Omega$ resistor from $\mathrm{ADC}$ input to ground is chosen to minimize current flowing to ground. 


\section{(b) The Circuit Diagram}

The circuit diagram is shown thus -

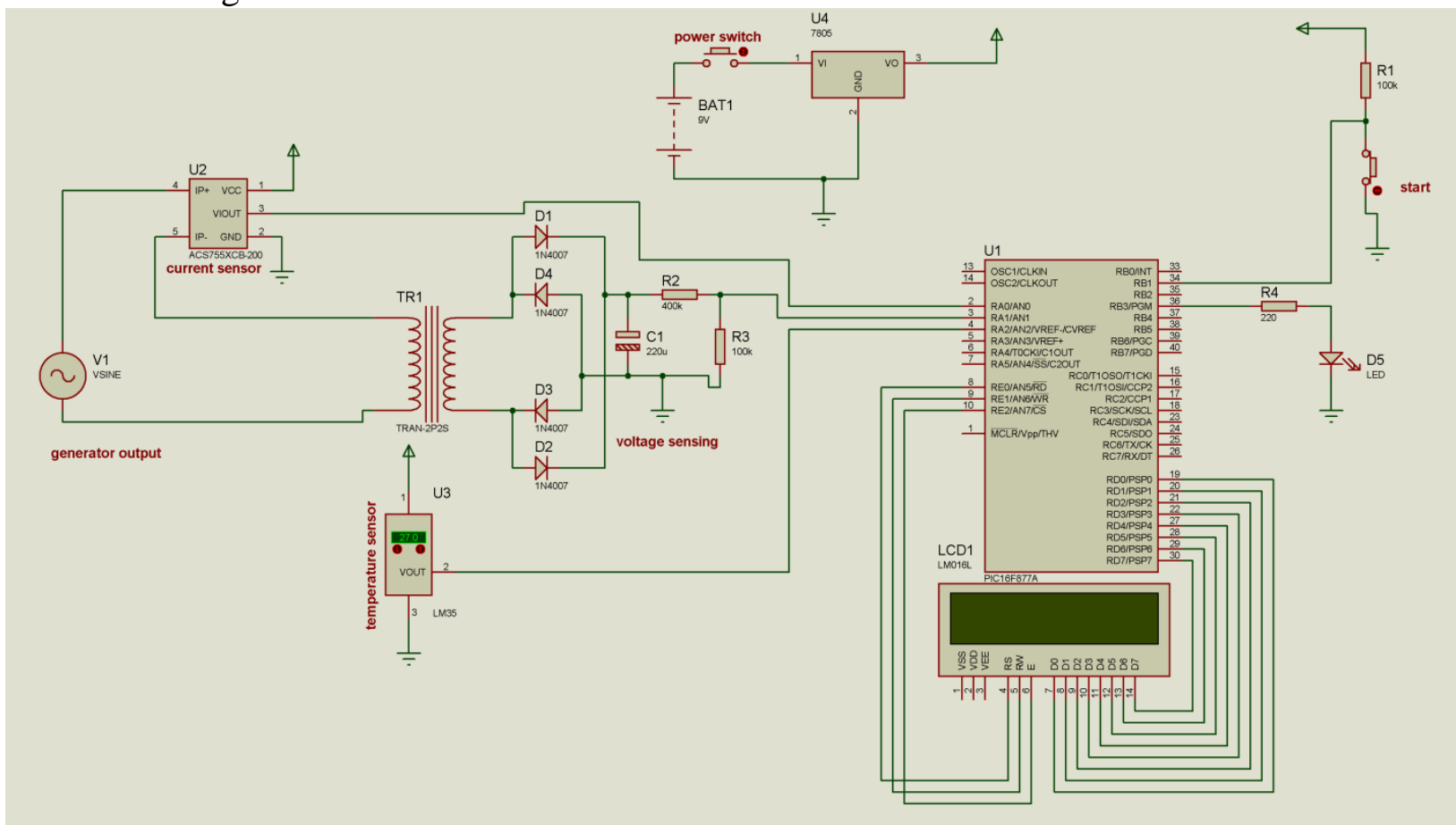

Figure 2: the circuit diagram

\subsection{Discussion of Result}

The table below shows the results gotten when the VIEW button is pressed. This allows us to show good plant output and identify anomaly as opposed to a generator (in an industrial power plant operating without the module) that simply stays on once it is switched on.

Table 4.1 implementation result

\begin{tabular}{|l|l|l|l|l|l|}
\hline S/no & $\begin{array}{l}\text { Generator } \\
\text { temperature. }\left({ }^{\circ} \mathrm{C}\right)\end{array}$ & $\begin{array}{l}\text { Output } \\
\text { current.(A) }\end{array}$ & $\begin{array}{l}\text { Output } \\
\text { voltage.(V) }\end{array}$ & Time (sec) & $\begin{array}{l}\text { Generator } \\
\text { status(without } \\
\text { module) }\end{array}$ \\
\hline 1 & 35 & 50 & 240 & 1 & On \\
\hline 2 & 35 & 50 & 240 & 2 & On \\
\hline 3 & 35 & 50 & 240 & 3 & On \\
\hline 4 & 35 & 50 & 240 & 4 & On \\
\hline 5 & 35 & 50 & 240 & 5 & On \\
\hline 6 & 36 & 30 & 180 & 6 & On \\
\hline 7 & 36 & 5 & 100 & 7 & On \\
\hline 8 & 35 & 25 & 170 & 8 & On \\
\hline 9 & 36 & 50 & 240 & 9 & On \\
\hline 10 & 37 & 50 & 240 & 10 & On \\
\hline 11 & 37 & 50 & 240 & 11 & On \\
\hline 12 & 37 & 51 & 240 & 12 & on \\
\hline
\end{tabular}




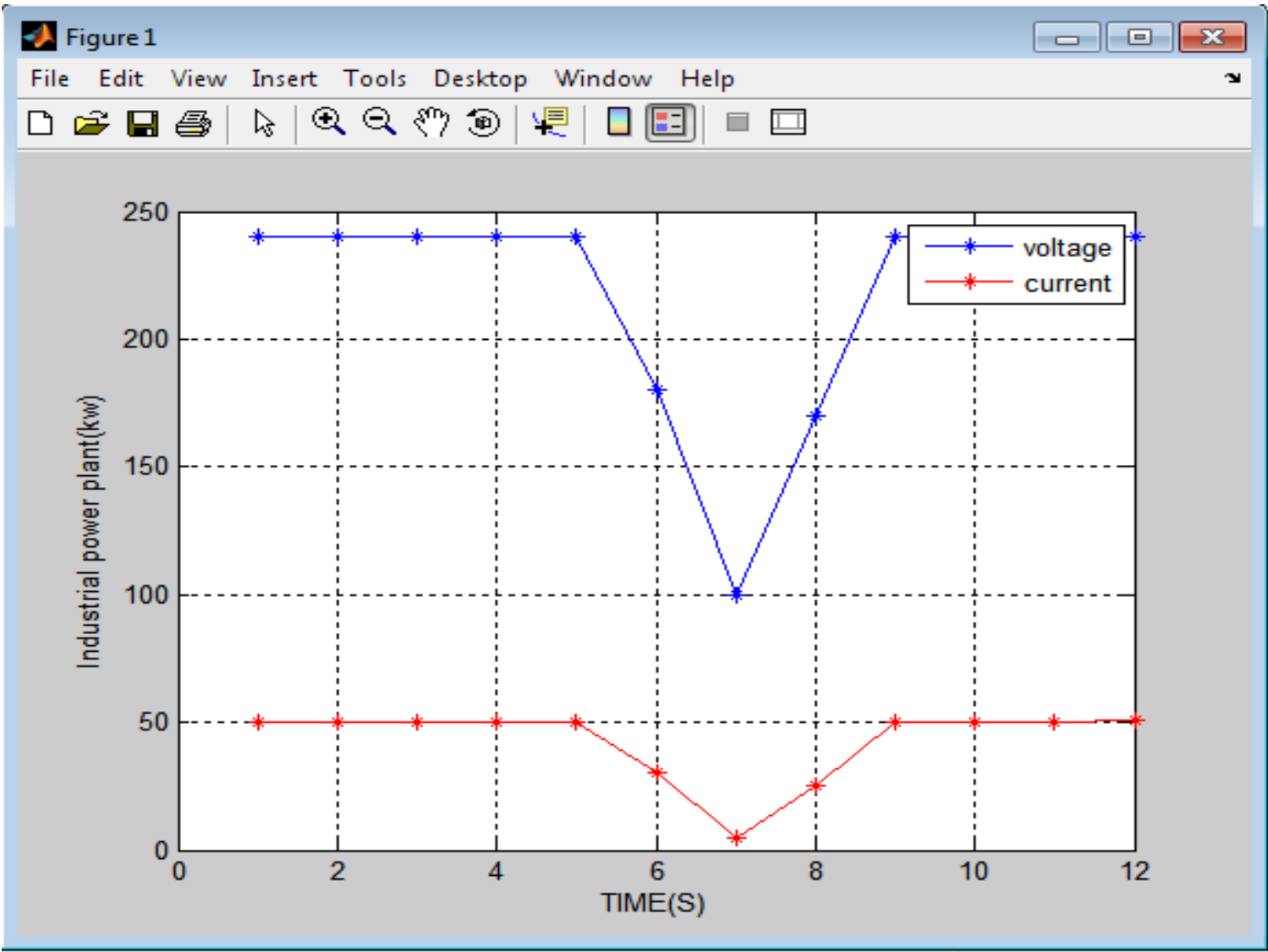

Figure3: The industrial power plant module of voltage and current

The figure 2 shows the module of power plant which sinuates instability system between time 5 to 9 seconds for voltage, current and operational frequency. Therefore there is an increase in generator temperature when the output voltageincreases.

The output voltage of the individual generator is then aggregated to get the output voltage of the industrial power plant. Using the module to monitor the voltage from each generator in the plant makes for a more effective system.

\section{Conclusion}

The principle of industrial power plant control was achieve through hardware components; a PIC16F877A microcontroller for measurements and the processing of information, LCD to display information to the user, LM35 temperature sensor to monitor temperature, ACS 758 Hall Effect current sensor to monitor the current, a $240 \mathrm{v}$ to $12 \mathrm{v}$ voltage transformer to monitor the output voltage and buttons for human interaction. The main state for monitoring module is a PIC16F877A microcontroller which has a firmware (software) running on it. There will be one plant to be controlled as its output voltage, output current and machine temperature is monitored. The module software is designed to implement the software of analogue voltage from the LM35 temperature sensor, ACS758 current sensor and the voltage sensor and convert these to digital voltages. MPLAB IDE software was used to carry out simulations to monitor and control industrial power plant. The ACS 758 hall effect current sensor, LM35 temperature sensor, a special step down transformer and a PIC16F877A microcontroller was put together to develop a module which records very high accuracy in monitoring the industrial power plant. 


\section{Reference}

1] D.McNamara, "temperature measurement theory and practical techniques", Analog Devices AN-F92 Application note.

2] G.G.Wolzak, 1983, "the development of high voltage measuring techniques", Technischeuniversiteit Eindhoven, DOI 10.6100/IR34982.

3] J.C.Santos, J.C.J.Almeida, L.P.C.Silver, "white light sensing systems for high voltage measuring using electro-optical modulators as sensor and recovery interferometers"

4] J.Stiles, 2004, "A mathematical description of BJT behavior", the university of Kansas department of EECS.

5] K.Barczak, 2011,'Optical fibre current sensor for electrical power engineering”, Bulletin of the polish academy of sciences technical sciences vol159 no 4.

6] K.Bohnert, P.Gabus, H.Brandle, 2003,"fibre optical current and voltage sensors for high voltage substations", $16^{\text {th }}$ international conference on optical fibre sensors Japan, technical digest pp752 - 754 .

7] M.Linder, 2001, “dc parameter extraction and modeling of bipolar transistors", KTH Royal Institute of Technology Stockholm Sweden 2001.

8] P.Hrdlicka, P.Neuman, B.Sulc. 2002,"process instrumentation modular models of thermal power plants for operator training simulators", 2002 IFAC $15^{\text {th }}$ triennial world congress, Barcelona Spain.

9] S.Kagitha, T.S.S Phani, A.Pravin,2014,"sensor network based thermal interlock control and remote monitoring system", International Journal of Innovative Research in Science, Engineering and Technology Vol3 issue12 ISSN 2319-8753.

10] R.Zivanoic, "high voiltage measurements", electrical engineering vol II encyclopedia of life support systems (EOLSS).

11] S.Osgood, M.Oljaca, "tips and tricks in industrial power measurements"

12] W.Koon,"current sensing for energy metering", Analog Devices Inc. 